\title{
Symposium review: Immunological detection of the bovine conceptus during early pregnancy*
}

\section{Troy L. Ott†}

Department of Animal Science, Center for Reproductive Biology and Health, Huck Institutes of the Life Science, Pennsylvania State University, University Park 16802

\section{ABSTRACT}

Infertility and subfertility reduce the economic viability of dairy production. Inflammation reduces conception rates in dairy cattle, but surprisingly little information exists about the populations and the functions of immune cells at the conceptus-maternal interface during the periattachment period in dairy cattle. Early pregnancy is accompanied by immune stimulation at insemination and conceptus secretion of IFN- $\tau$, pregnancy-associated glycoproteins, prostaglandins, and other molecules whose effects on immune function during early pregnancy have not been determined. Our working hypothesis is that pregnancy induces changes in immune cell populations and functions that are biased toward immunological tolerance, tissue remodeling, and angiogenesis. This review summarizes current knowledge, starting with insemination and proceeding through early pregnancy, as this is the period of maximal embryo loss. Results indicated that early pregnancy is accompanied by a marked increase in the proportion of endometrial immune cells expressing markers for natural killer (CD335) cells and cytotoxic $\mathrm{T}$ cells $(\mathrm{CD} 8)$ along with an increase in cells expressing major histocompatibility class II antigens (macrophages and dendritic cells). This is accompanied by increased abundance of mRNA for IL-15, a natural killer growth factor, and IL-10 in the endometrium during early pregnancy. Furthermore, expression of indoleamine 2,3 dioxygenase was 15 -fold greater in pregnant compared with cyclic heifers at d 17 , but then declined by $\mathrm{d} 20$. This enzyme converts tryptophan to kynurenine, which alters immune function by creating a localized tryptophan deficiency and by activation of the aryl hydrocarbon receptor and induction of downstream tolerogenic mediators. Expression of the aryl

\footnotetext{
Received September 9, 2018.

Accepted November 20, 2018.

*Presented as part of the Joint ADSA/SSR Symposium: The Immune-Reproduction Nexus-The Good, the Bad, and the Ugly at the ADSA Annual Meeting, Knoxville, Tennessee, June 2018.

$\dagger$ Corresponding author: tlo12@psu.edu
}

hydrocarbon receptor is abundant in the bovine uterus, but its temporal and spatial regulation during early pregnancy have not been characterized. Pregnancy is also associated with increased expression of proteins known to inhibit immune activation, including programed cell death ligand-1 (CD274), lymphocyte activation gene-3 (CD223), and cytotoxic T-lymphocyte associated protein-4 (CD152). These molecules interact with receptors on antigen-presenting cells and induce lymphocyte tolerance. Current results support the hypothesis that early pregnancy signaling in dairy heifers involves changes in the proportions of immune cells in the endometrium as well as induction of molecules known to mediate tolerance. These changes are likely essential for uterine wall remodeling, placentation, and successful pregnancy.

Key words: bovine, immune, conceptus, lymphocyte, uterus

\section{INTRODUCTION AND HISTORICAL PERSPECTIVE}

This review is a synthesis of recent developments in understanding about the earliest immunological signaling between the conceptus and dam in cattle. Although some reference will be made to nonruminant species, comprehensive reviews covering domestic farm species other than ruminants are available (Meeusen et al., 2001; Croy et al., 2009). This review will also focus on early pregnancy, attempting to integrate recent results describing changes in endometrial immune status at the onset of conceptus IFN- $\tau$ production (Kamat et al., 2016; Vasudevan et al., 2017). Excellent reviews cover the entire span of pregnancy or focus on changes occurring during later gestation and around parturition in ruminants (Hansen and Tekin, 2005; Hansen, 2010; Oliveira et al., 2012; Fair, 2015).

The question of whether a cow "settled" following insemination is as old as animal agriculture. Historically, the challenge was 2-fold; first, making sure the cow was exposed to the bull at the appropriate stage of the estrous cycle to conceive, and second, determining whether the pregnancy actually "took" so the cow 
would deliver a healthy calf. Detection of the conceptus was a high-stakes event for early farmers, and failure of a cow to calve could mean the difference between health and prosperity and hunger and poverty.

As animal scientists began to understand the physiology of early pregnancy, R. V. Short conceptualized the biology of conceptus detection with the phrase "maternal recognition of pregnancy" (see Bazer, 2015), which referred to maternal responses to the conceptus. These responses resulted in rescue of the corpus luteum and continued production of progesterone. For the cow and related ruminants, this was a direct response to conceptus signaling mediated by the uterus. For farmers, maternal recognition of pregnancy allowed for indirect detection of the conceptus (pregnancy) by monitoring changes in maternal physiology (production of progesterone and suppression of estrous behaviors).

Greater insight into signaling between the dam and conceptus yielded a growing recognition that pregnancy was not binary (it was not merely pregnant or not pregnant); rather, there were degrees of quality of the pregnancy. It became increasingly clear that suboptimal pregnancies could have lifelong (programming) effects on the offspring (growth, production, health). This concept took hold with the work of David Barker studying human offspring from the Dutch Hunger Winter during World War II as they matured through adulthood (Barker, 1998). The key finding underpinning the Barker Hypothesis (also known as the thrifty phenotype hypothesis) was that fetuses that were gestated under starvation conditions were able to progress to term but they exhibited an increased incidence of a variety of chronic diseases as they matured into adulthood and old age. Thus, fetuses gestated in nutritionally restricted conditions developed a thrifty phenotype to ensure their survival if these conditions persisted after birth. However, this fetal programming had consequences for the length and quality of life. In a practical sense, dairy farmers understand that birth weight is correlated with weaning weight and lifetime productivity (Rumph and Van Vleck, 2004; Kertz et al., 2017). Advances in genetics and epigenetics are beginning to reveal the myriad ways the dam "detects," responds to, and can program the conceptus that have lifelong implications for the offspring (Sandra et al., 2015).

Central to this communication is the establishment of a placenta-the structural, metabolic, endocrine, and immune interface between the fetus and the mother (Schlafer et al., 2000; Peter, 2013). It is a partnership with risks and rewards for the mother, and its formation requires a biochemical dialog to be established with the conceptus. Sir Joseph Barcroft captured the importance of the placenta and the essence of this dia- log when he eloquently stated, "the stage is set before the play commences" (Barcroft, 1934). With this statement, he intimated that the quality of the pregnancy is dictated by the quality of the placenta (the stage) which grows first, "anticipating" the needs of the fetus in late pregnancy (Barcroft and Barron, 1946). And although early studies focused on structural, metabolic, and endocrine aspects of the placenta, this changed with the understanding that the quality of the placenta traces back to the earliest signals between placenta and conceptus occurring during the peri-implantation period. It soon became clear that this close association between tissues (placental and uterus) of genetically distinct individuals was unique.

The truly remarkable nature of this histo-incompatible partnership was compellingly articulated by Sir Peter Medawar more than $60 \mathrm{yr}$ ago (Beer and Billingham, 1970). Medawar, a transplantation biologist, is credited with establishing the field of reproductive immunology, with early studies on the mechanisms of tissue transplant rejection and contributions to understanding the role of histocompatibility molecules in this process. Equipped with new insight into how the immune system rejects transplanted tissue from individuals that were not histocompatible, Medawar was struck by how the mother could gestate an immunologically distinct (semi-allogeneic) conceptus for the course of gestation without provoking an immune response that would reject the fetal allograft. To explain this phenomenon, he put forward 3 postulates: (1) the placenta is a barrier to maternal immune cells; (2) the mother is immunologically suppressed during pregnancy; and (3) the conceptus "hides" from the mother's immune system by altering expression of histocompatibility molecules. More than $60 \mathrm{yr}$ after his observations on the enigma of viviparity, there is still much to learn about this transient relationship that is essential for survival for all viviparous species.

\section{BRIEF OVERVIEW OF THE IMMUNE SYSTEM}

The bovine immune system participates in a complex series of cellular interactions essential for life (Lippolis, 2008; Sordillo, 2016). These interactions are designed to detect and eliminate invading pathogens and stressed or damaged cells or tissues. They mediate angiogenesis and hemostasis and participate in tissue homeostasis. Cells of the immune system contain surface proteins that receive and transmit instructions from and to somatic cells and between one another. They release and respond to activating, inhibiting, and summoning hormones (cytokines) that result in a finely tunable response tailored to the challenge. Specific immune cell subtypes carry hydrolytic enzymes and reactive oxygen 
species that kill damaged or infected cells and they possess phagocytic activity to engulf pathogens and debris for removal, recycling, and tissue repair. Other cell types produce antibodies that coat invaders to aid in their phagocytosis and clearance from the body.

Interestingly, the immune system is "teachable." First, during development, the immune system is educated to differentiate self from non-self and, later, following a pathogen challenge, memory cells "remember" the nature of foreign invaders so that subsequent invasions are repelled more rapidly. This memory component of the immune system is the biological underpinning of vaccination programs, and is arguably one of the greatest health advances in the history of agriculture and medicine (Ball et al., 1998). Thus, the immune system of multicellular organisms sits at the very core of physiological processes that mediate life and death.

The most primitive component of the immune system is the innate arm, consisting of phagocytic cells containing hydrolytic enzymes that can punch holes in membranes and engulf and destroy pathogens and damaged or infected cells. Granulocytes (neutrophils, basophils, and eosinophils), monocytes, macrophages, and dendritic cells are the primary cellular components of innate immunity. Neutrophils are abundant, short-lived, phagocytic granulocytes that contain enzymes and bactericidal proteins and peptides among other powerful chemical mediators (Bassel and Caswell, 2018). Neutrophils are an abundant leukocyte in the blood and they are the first responders during an infection, engulfing and destroying pathogens while components of the adaptive immune system are called to the site of infection and educated about the nature of the pathogen.

Monocytes circulate in the blood until called into tissues where they differentiate into macrophages and dendritic cells. Monocyte-derived macrophages are the aptly named "big eaters." Macrophages play complex roles in the immune response that range from proinflammatory (M1) to anti-inflammatory (M2) phenotypes (Hussen and Hans-Joachim, 2017). Macrophages phagocytize at the site of infection or damage, and they summon and educate other immune cell types by displaying small fragments of the invading pathogen (antigen presentation) to cells of the adaptive arm of the immune system and providing cytokine signals to help direct their development. These antigens, displayed on the cell surface along with the cytokines released by macrophages, help educate bone marrow-derived B cells and thymus-derived $\mathrm{T}$ cells. The $\mathrm{T}$ cells can be activated to $\mathrm{T}$ helper (Th)1, Th2, Th17, and T regulatory (Treg) phenotypes that shape the immune cell's response to a pathogen (Lippolis, 2008). Macrophages also help turn off an immune response to limit tissue damage. For example, they produce anti-inflammatory cytokines including IL-10 and IL-4 that inhibit further Th1 activation and promote Th2 cell proliferation. Active Treg cells play a similar role in resolving the immune response to infection. This provides for a balanced response to infection designed to defeat the invaders but also limit tissue damage resulting from inflammation.

Dendritic cells populate the outer boundaries of mucosal tissues, including the reproductive tract, engulfing particles from their surroundings. Once activated by a pathogen, dendritic cells leave the tissue via the lymphatic system and travel to draining lymph nodes, where they present their antigens to $\mathrm{T}$ and $\mathrm{B}$ cells and alert them to the nature of the invading pathogen. In this regard, dendritic cells serve as "sentries on the castle walls" ready to raise the alarm of incoming invaders.

Macrophages and other antigen-presenting cells (APC) also display antigens to $\mathrm{B}$ cells, and the B cells that bind the antigen are stimulated to proliferate rapidly and transform into plasma cells that can produce thousands of antibody molecules per second targeted against the invading pathogen (Prieto and Felippe, 2017). Professional APC, such as macrophages and dendritic cells, display antigens bound to major histocompatibility complex (MHC) class II molecules (MHC II). Antigen presentation provides information about the nature of the pathogen along with co-stimulatory signals that help direct the adaptive immune response.

Somatic (nonimmune) cells also display antigens on their surface that can activate immune cells but use MHC class I molecules instead. Molecules presented with class I MHC on somatic cells activate cytotoxic $\mathrm{T}$ and natural killer (NK) cells and result in cell killing. Interestingly, expression of class I MHC molecules is routinely "reviewed" by NK cells. Somatic cells not expressing class I MHC or expressing class I MHC bound to molecules associated with cellular stress or damage can trigger NK cell killing (Boysen and Storset, 2009). In this regard, class I MHC is a type of cellular identification card that must be correctly displayed to avoid NK attack. Inappropriate expression of class I MHC allows NK cells to identify and eliminate cancer cells. It is these MHC molecules that define "self" and that must be closely matched to allow for successful tissue transplantation. Class I MHC are highly variable between individuals, and the early study of these histocompatibility molecules is what stimulated Medawar to ponder how the mother's immune system tolerated paternal MHC I expression on cells of the developing conceptus during pregnancy.

Thus, the immune system is prepared to immediately defend the body using physical and chemical barriers 
and secreted antimicrobial and immune-modulating proteins and via activation of innate immunity triggered by recognition of pathogen-associated molecular patterns (PAMP). This rapid and robust response is typically sufficient to fight off invaders. If this is not the case, innate immunity buys time to allow the adaptive immune system to be activated and deploy a potent army of antibody-producing $\mathrm{B}$ and $\mathrm{T}$ cells specifically tuned to the invader. For a more detailed review of the immune system, the reader is directed to several excellent reviews (Lippolis, 2008; Sordillo 2016).

\section{IMMUNOLOGICAL DETECTION OF THE BOVINE CONCEPTUS}

\section{Mating-Induced Immune Response}

Before discussing immune detection of the early conceptus, it is important to point out that the first immune stimulus associated with establishment of pregnancy occurs at mating. Several labs have demonstrated that insemination results in a robust maternal immune response in the female reproductive tract (reviewed by Schjenken and Robertson, 2014, and Bromfield, 2018). This is especially true in intrauterine inseminating species such as swine and horses, but also holds for cattle and sheep (Bischof et al., 1995; Portus et al., 2005; Scott et al., 2009; Bromfield, 2018). This is not surprising given the large number of antigens introduced into the female reproductive tract at mating and the existence of sexually transmitted infections. Evidence indicates that this first signaling is important for fertility and optimal pregnancy in rodents. However, in cattle, the importance of this signaling is currently not clear. The fact that embryo transfer results in high pregnancy rates also suggests that there is no absolute requirement for immunological signaling before the onset of conceptus elongation around d 13 to 15 of pregnancy. Furthermore, adding seminal plasma back at insemination in dairy and beef cattle did not improve pregnancy rates (Odhiambo et al., 2009). Pregnancy rates following embryo transfer are typically equal to or greater than those obtained by natural mating or the best AI programs. However, what remains to be determined is whether the immune response to insemination has programming effects on the mother or conceptus that affect the quality of the offspring (Bromfield, 2018).

\section{Immunological Recognition of the Conceptus}

Following hatching from the zona pellucida around Day 8 to 9 , the conceptus has several major hurdles to overcome during the periattachment period. It must ensure continued progesterone production by the cor- pus luteum. It must avoid attack by maternal immune cells and induce endometrial remodeling to support formation of the placenta. These 2 tasks are accomplished, in part, by redistributing maternal immune cells and altering their function to ensure the appropriate maternal response to conceptus alloantigens (Oliveira et al., 2012, 2013; Hansen, 2014; Ott et al., 2014). However, relatively little is known about the effects of the conceptus or its secretions on the proportions and function of uterine immune cells during the period of maternal recognition of pregnancy in cattle (d 15-20).

Conceptus signals drive immune responses toward tolerance and secretion of cytokines that promote placental growth and function. This shift is characterized by reduced expression of cytokines associated with inflammation (Th1/Th17) and increased expression of cytokines that suppress inflammation (Th2; Wegmann et al., 1993; Oliveira et al., 2013). This theory, referred to as the Th1-Th2 shift, has strong support in the literature. However, it oversimplifies the diverse array of immune cell responses typically observed during early pregnancy. Furthermore, this terminology relates primarily to immune responses to pathogens. Clearly, pregnancy is a different stimulus for the immune system. In addition, although these terms may help define the immune response, pregnancy-induced immune changes clearly involve both activation and suppression of immune functions (Oliveira et al., 2013; Ott et al., 2014; Kwak-Kim et al., 2014; Hansen, 2014). Relatively little is known about the effects of pregnancy, IFN-T (IFNT) or other conceptus secretory proteins on uterine immune cells during the periattachment period in dairy cattle (blastocyst hatching to $\sim \mathrm{d} 15$ to 25 ). This is a period of substantial embryo loss (Diskin et al., 2011).

\section{Local (Uterine) Immune Responses to the Conceptus}

Several studies have examined the endometrial transcriptome during the periattachment period in cattle, and these studies consistently identify immune function genes and pathways as being the most highly regulated during early pregnancy (Spencer et al., 2008; Walker et al., 2010; Cerri et al., 2012; Bauersachs and Wolf, 2015). Fewer studies focus on changes in uterine immune cell populations in ruminants during this same time (Leung et al., 2000; Oliveira et al., 2013; Kamat et al., 2016; Vasudevan et al., 2017) compared with more extensive literature for later pregnancy and the periparturient period (Nasar et al., 2002; Tekin and Hansen, 2002; Oliveira and Hansen, 2008, 2009; Oliveira et al., 2010; Fox et al., 2010). Furthermore, much of the work in this field occurred more than 15 yr ago, when cellular morphology alone (Vander Wielen and King, 1984) or poorly characterized antibodies (Gongolin-Ewens 
et al., 1989; Lee et al., 1988) were used to identify immune cell populations. In addition, many of these studies were done in sheep or involved too few animals or slaughterhouse specimens of uncertain staging to evaluate uterine immune cell populations. Furthermore, differences exist in immune response to pregnancy, even among species as closely related as sheep and cattle (Lewis et al., 2007). For these reasons, understanding the phenotypes and functions of immune cells present in the uterus during the periattachment period is essential to understanding factors regulating fertility in dairy cattle.

Natural killer cells (Vasudevan et al., 2017) and macrophages or dendritic cells (Oliveira and Hansen, 2009; Kamat et al., 2016) were shown to be proportionally increased in the endometrium during early pregnancy in dairy heifers. These cells were also implicated as key mediators of conceptus signaling during early pregnancy in rodents and humans (Kwak-Kim et al., 2014). Natural killer cells are a potential threat to the developing conceptus due to their ability to kill without co-stimulation. Because of their ability to identify foreign MHC I molecules (or the absence of MHC I), NK cells create an immunological challenge for an allogeneic conceptus. This could be overcome by exclusion of the NK cells from the fetal-maternal interface, or by conceptus signals that alter NK cell function. However, there is little evidence that NK cells are excluded from the fetal-maternal interface. Vander Wielen and King (1984) described a distinct population of endometrial NK-like lymphocytes in cyclic cattle. These cells expressed the protein tyrosine phosphatase receptor type $\mathrm{C}$ (PTPRC or CD45) that is expressed on most leukocytes, but stained weakly for CD5 (T and certain B cells) and surface immunoglobulins indicative of B cells (Lee et al., 1988). Because these cells often contained 1 to 3 large membrane-bound granules, they were postulated to be NK cells. These granules contained lytic enzymes including perforin, granzymes, and granulysin that damage cell membranes. Natural killer activity in the uterus was later confirmed, although their functional status during early pregnancy in cattle remains to be elucidated (Segerson and Beetham, 2000; Tekin and Hansen, 2002). Natural killer cells contribute to placentation in humans and rodents by modifying maternal spiral arteries to support placental vascular development (Kane et al., 2009; Lash et al., 2016). Interestingly, uterine NK cells in humans do not exhibit cytolytic activity but rather appear to participate in establishing a regulatory environment by production of Th2 cytokines (Mori et al., 2016). Disruption of NK cell function contributes to several human reproductive disorders (Lash and Bulmer, 2011). Once again, there is a large proportional increase in endometrial
CD45+ immune cells expressing the NK marker NKp46 in early pregnant heifers. And, although they are not the most abundant immune cell type detected at the fetal-maternal interface, results suggest that NK cells are involved in the establishment of pregnancy in dairy cattle (Vasudevan et al., 2017).

Both cytotoxic (CD8+) and helper (CD4+) T cells are present in the ruminant uterus during early pregnancy. Helper $\mathrm{T}$ cells direct immune responses by the production of inflammatory (Th1) or regulatory (Th2) cytokines. These cytokines direct effector responses of $\mathrm{CD} 4+\mathrm{T}$ cells toward the elimination of specific classes of pathogens. Cytokine-induced Th1 cells eliminate intracellular viruses and bacteria, whereas Th2 cells are more effective at eliminating extracellular parasites and Th17 cells on extracellular bacteria and fungi. Cytotoxic $\mathrm{T}$ cells both produce and respond to some of these same cytokines and can participate directly in killing target cells using some of the same mechanisms described for NK cells. Approximately $25 \%$ of uterine cytotoxic T cells in sheep express the gamma delta $(\gamma \delta+) \mathrm{T}$ cell receptor, whereas the remaining $75 \%$ express the $\alpha / \beta$ $\mathrm{T}$ cell receptor. As with NK cells and $\alpha / \beta$ cytotoxic $\mathrm{T}$ lymphocytes, the cytoplasmic granules of $\gamma \delta \mathrm{T}$ cells contain perforin and granzymes, further supporting a killing phenotype for these cells (Fox et al., 2010). This cell population represents a potential danger to the developing conceptus (Fox et al., 2010). The $\gamma \delta+$ T-cell population increases dramatically in the uterus toward the end of gestation, as does their granularity (Meeusen et al., 1993), suggesting that these cells may be involved in parturition and shedding of the placenta. Regulation of $\gamma \delta+\mathrm{T}$ cells during early pregnancy in cattle is largely unknown (Hansen, 2014). There is, however, a large increase in the relative proportion of immune cells expressing CD8 at the conceptus-maternal interface during early pregnancy (Vasudevan et al., 2017). Based on the large proportional increases in both NK and CD8+ cells during early pregnancy, we hypothesized and then confirmed that these proteins were co-expressed on a population of endometrial immune cells. Furthermore, mRNA abundance of granzyme A was greater in the endometrium of pregnant compared with cyclic heifers at d 17. However, mRNA abundance of granzyme A then decreased between $\mathrm{d} 17$ and 20 of pregnancy, accompanied by increased expression of CD107a, a marker of degranulation in CD45+ lymphocytes (Vasudevan et al., 2017).

Co-expression of NK and CD8 on the same cells is not common in cattle. There is evidence for expression of NK receptors on $\gamma \delta+$ and CD8+ cells treated with IL15 or transforming growth factor- $\beta$ (TGFB; McMahon and Raulet, 2001; Johnson et al., 2008; Tilburgs et al., 2009). In cattle, NK cells in the lymph nodes and a 
subset of peripheral NK cells expressed CD8 (Boysen et al., 2008). It could be argued that NK cells expressing CD8 protein are NK T cells. A characteristic feature of NK T cells in other species is CD1d receptor-mediated antigen presentation. However, CD1d is a pseudogene in the cattle genome (Van Rhijn et al., 2006), making it unlikely that these cells are NK T cells. Recent work by Connelley et al. (2014) showed a population of unconventional CD3+ NK cells that could respond both to NK and T-cell receptor stimulation (Connelley et al., 2014). Furthermore, uterine NK cells are present during early pregnancy in pigs and most express the CD8 protein, albeit at low levels (dim; Croy et al., 1988). A population of $\mathrm{CD} 8 \alpha^{\mathrm{dim}} / \mathrm{NK}+$ cells in pigs expressed an activated NK phenotype with high CD16 and CD27 expression and increased production of IFN- $\gamma$ and tumor necrosis factor following stimulation. This CD8 ${ }^{\mathrm{dim}}$ subset of NK cells also exhibited a greater cytotoxic potential (Mair et al., 2013). We hypothesize that IFN- $\tau$ induces the proportional increase in NK cells expressing CD8 during early pregnancy, but this speculation has yet to be confirmed experimentally.

Considering the presence of NK and cytotoxic T cells at the fetal-maternal interface, regulatory mechanisms must be in place to protect the conceptus from attack. Presumably, progesterone-mediated suppression of $\mathrm{T}$ cell activation and expression of uterine serpins, galectins, and pregnancy-induced blocking factor, are among these (Froehlich et al., 2012; Hansen, 2014). Uterine immune cells and parenchymal cells express regulatory cytokines that can affect immune cell function. For example, mRNA abundance of IL10 is increased in the endometrium and in the CD45+ immune cell fraction (Vasudevan et al., 2017). Furthermore, the potent immune regulator indoleamine 2,3 dioxygenase 1 (IDO1) was elevated in pregnant compared with cyclic heifers on d 17 and then decrease on d 20, and IDO1 protein was localized to both immune and nonimmune cells in the endometrium of dairy heifers (Kamat et al., 2016). Similar increases in IDO1 were detected during early pregnancy in cattle (Groebner et al., 2011), humans, and rodents (von Rango et al., 2007; Jeddi-Tehrani et al., 2009), suggesting a possible conserved role for kynurenine signaling or need for a transient reduction in tryptophan concentrations at the fetal-maternal interface.

Only a few reports have characterized leukocyte populations in the endometrium during the periattachment period in cattle. Leung et al. (2000) demonstrated the presence of $\mathrm{CD} 4+$ ( $\mathrm{T}$ cells $), \mathrm{CD} 21+(\mathrm{B}$ cells $)$, and CD14+ (macrophage/dendritic cells) on Day 16 of pregnancy. However, they did not detect any differences in the proportions of these cells between cyclic and pregnant heifers on Day 16. Interestingly, many
CD14+ cells were detected in the endometrium and subepithelial stroma (Leung et al., 2000). Similarly, CD14+ CD68+ cells (macrophages) are present in the endometrium of cyclic ewes (Tekin and Hansen, 2004). The number of these cells increased substantially later in pregnancy in the cow and expressed genes associated with a regulatory phenotype, including the mannose receptor C, type 1 (MRC1) and CD163, also known as the scavenger receptor (Oliveira and Hansen, 2008; Oliveira et al., 2010). Work by Mansouri-Attia et al. (2012) quantified macrophage/dendritic cells in the endometrium and demonstrated that a CD11c+ fraction (dendritic cells) expressing signal-regulatory protein $\alpha$ (SIRPA; a mediator of tolerance) increased in the endometrium on Day 16 of pregnancy in beef heifers. Dendritic cells are the key APC that regulate activation status of the immune system. Furthermore, APC (macrophages and dendritic cells) detected using antibodies that recognize MHCII proteins increased in the endometrium during early pregnancy (Days 17 to 20; Kamat et al., 2016). The greatest increases occurred adjacent to the shallow and deep glands of the endometrium. This was accompanied by increased mRNA abundance for MHCII, CD80, CD86, and CD163, providing further evidence that these cells are macrophages. Abundance of both SIRPA and CD163 also increased, suggesting that these cells exhibit a nonactivated, immature, or regulatory phenotype (Kamat et al., 2016). The presence of macrophages and dendritic cells at the conceptus-maternal interface during early pregnancy might promote conceptus survival by stimulating expression of immunoregulatory molecules such as prostaglandin (PG) E2, IL10, IL4, and IDO (Munn et al., 1998; Nagamatsu and Schust, 2010; Groebner et al., 2011). We hypothesize that the conceptus induces expression of IDO, leading to increased production of kynurenine and induction of regulatory cytokines such as IL10 and TGFB via activation of the aryl hydrocarbon receptor (AHR).

It is now clear that conceptus IFNT affects immune function genes in both the uterus and peripheral blood (Yankey et al., 2001; Han et al., 2006; Gifford et al., 2007; Ott and Gifford, 2010). In addition, there is considerable expression of IFN-stimulated genes in uncharacterized populations of endometrial immune cells (Gifford et al., 2008; Song et al., 2007). Type I interferons, including IFNT, promote immunosuppressive functions including the induction of Treg. For instance, IFNT-treated CD4+ cells exhibit regulatory activity by expressing TGFB and IL10 (Mujtaba et al., 1997). Furthermore, expression of mRNA and protein IL10 was detected in total endometrium during early pregnancy (Kamat et al., 2016). Obvious candidates mediating the effects of IFNT on uterine function in- 
clude the transcription factors IFN regulatory factor (IRF)1 and IRF2. Spencer et al. (1998) showed that pregnancy and IFNT sequentially induced IRF1, a transcriptional activator, and IRF2, a transcriptional repressor. Both transcription factors regulated expression of genes containing interferon-stimulated response elements (ISRE). Through this mechanism, IFNT blocks the cyclic upregulation of estrogen receptors in the sheep endometrium (Spencer et al., 1998). Relatively less is known about IFNT signaling in cattle, but Telgmann et al. (2003) showed that IRF1 and IRF2 are expressed in the endometrium during early pregnancy in cattle and regulate the oxytocin receptor in the endometrium. Groebner et al. (2011) also detected IRF2 in the bovine endometrium on Day 18, but they did not examine later days of pregnancy. Interestingly, the gene for IDO1 contains an interferon-stimulated response element and is known to be regulated by type I and type II IFN (Hassanain et al., 1993). Therefore, IFNTactivated IDO1 expression could induce tolerance in endometrial immune cells via activation of AHR.

Indoleamine 2,3-dioxygenase is the first enzyme in the pathway of tryptophan metabolism to kynurenine, kynurenic acid, and quinolinic acid (Groebner et al., 2011). Activation of IDO1 is considered a key component mediating immune tolerance and resolution of inflammation, especially in pregnancy (Mellor and Munn, 2001; Li et al., 2013). For example, IDO1 expression increased at implantation sites in rodents and blocking IDO1 expression resulted in inflammation and loss of allogeneic but not syngeneic pregnancies (Mellor and Munn, 2001). Expression of IDO1 was elevated in the bovine endometrium at d 17 of early pregnancy (Groebner et al., 2011; Kamat et al., 2016) and then declined sharply by Day 20 of pregnancy (Kamat et al., 2016). The increase in IDO1 expression was accompanied by a decrease in the tryptophan/kynurenine ratio (Groebner et al., 2011). Kynurenine is a key mediator of the effects of IDO1 through its ability to bind and activate AHR and induce tolerogenic mediators (Vacca et al., 2010). Kynurenine, in the presence of TGFB, can convert naïve $\mathrm{T}$ cells into FoxP3+ regulatory $\mathrm{T}$ cells through AHR-mediated signaling (Gandhi et al., 2010; Mezrich et al., 2010). Moreover, IDO1 mediates the interaction between decidual NK cells and macrophages to promote tolerance in the human uterus. This mechanism involved induction of inhibitory proteins, including cytotoxic T-lymphocyte activating 4 (CTLA4) and TGFB (Vacca et al., 2010). Expression of CTLA4 increased in the bovine endometrium during early pregnancy (Vasudevan et al., 2017). The strongest labeling for CTLA4 was in and around the luminal epithelium and subepithelial stroma, adjacent to the conceptus-maternal interface.
Aryl hydrocarbon receptor is a ligand-activated nuclear transcription factor member of the basic helix-loop-helix (bHLH)-Per-ARNT-Sim (PAS) family of transcriptional regulators. When bound by ligand, AHR binds to response elements and promotes transcriptional activation of cytochrome P450 enzymes CYP1A1 and CYP1B1 (Nebert and Karp 2008). Peroxisome proliferator-activated receptor- $\gamma$ (PPARG) is a nuclear hormone receptor that is a target gene for AHR; PPARG agonists decrease pro-inflammatory cytokine production to induce tolerance (Ricote et al., 1998; Tugwood and Montague 2002). The presence of AHR is reported in human and rodent endometrium (Hernández-Ochoa et al., 2009; Jiang et al., 2010). Aryl hydrocarbon receptor and products of its activation, including CYP1A1 and PPARG, were detected in human placenta (Storvik et al., 2014). Bovine mammary parenchymal cells and cultured blood lymphocytes express AHR (Girolami et al., 2015), and our unpublished results show abundant expression of AHR in endometrial immune and parenchymal cells during early pregnancy in dairy heifers (T. L. Ott and M. Hartzell, Pennsylvania State University, unpublished data). We hypothesize that IDO1 increases tryptophan metabolites, including kynurenine, resulting in activation of the AHR to induce mediators of immune tolerance. Further, we postulate that IDO1 is then downregulated by conceptus IFNT or other conceptus secretions to promote tissue remodeling associated with the formation of a placenta. This speculation remains to be confirmed experimentally.

Finally, the conceptus secretes several molecules during early pregnancy in addition to IFNT that could affect immune function. Perhaps most well-known among this group is the pregnancy-associated glycoprotein (PAG) family (Butler et al., 1982; Sasser et al., 1986; Green et al., 2000). Although PAG family members are expressed at the conceptus-maternal interface starting at around Day 15 of pregnancy in cattle, their function remains an enigma (Wooding et al., 2005; Wallace et al., 2015). There is a 200-fold increase in pregnancyspecific protein B (PSPB; predominantly PAG1) in uterine flushes between Day 17 and 20 of pregnancy (T. L. Ott, S. Vasudevan, and M. Kamat, Pennsylvania State University, unpublished data). Pregnancyassociated glycoproteins are a large family of inactive aspartic proteinases, similar to pepsinogen (Garbayo et al., 2008). However, mutations around the catalytic site of PAG are thought to have rendered many of them inactive as proteases (Green et al., 2000; Wallace et al., 2015). Interestingly, PAG are still thought to be able to bind peptides, and it was suggested that this peptidebinding activity might be involved in their function during early pregnancy (Hughes et al., 2000). Indeed, 
Wooding et al. (2005) examined PAG localization at the conceptus-maternal interface and concluded that they were likely involved in immune regulation. This is supported by recent work of Thompson et al. (2012), who showed that PAG altered endometrial prostaglandin production in cattle. Finally, physiologically relevant concentrations of PSPB reduced endometrial T-cell proliferation in response to concanavalin A but did not affect proliferation of peripheral blood $\mathrm{T}$ cells ex vivo (S. Vasudevan, M. Kamat, and T. L. Ott, Pennsylvania State University, unpublished data). Taken together, these results lend support to the hypothesis that PAG participate in immune modulation at the conceptusmaternal interface during early pregnancy.

\section{Peripheral Immune Responses to the Conceptus}

Perhaps the earliest evidence of a peripheral immunomodulatory response to pregnancy was work showing that serum from pregnant mice inhibited rosette formation by anti-lymphocyte serum in vitro (Morton et al., 1974). This activity, termed early pregnancy factor $(\mathrm{EPF})$, appeared in the serum within hours of a fertile mating and was detected in humans, pigs, sheep, and cattle, suggesting broad evolutionary conservation of this response (reviewed by Morton, 1987). Interestingly, this factor was also produced by tumor cells and regenerating normal cells (Cavanagh, 1996). For almost 2 decades, the nature of the factor mediating this response eluded investigators, but it was finally determined to share homology with chaperonin 10, a member of the heat shock/chaperonin protein family that participates in protein folding and stabilization in a wide array of cellular contexts (Cavanagh, 1996; Morton, 1998). Chaperonin 10 (also known as HSP10 and HSPE1) is expressed in a wide array of cell types and has been shown to modulate immune cell function, for example, by inducing formation of Treg cells and production of IL10 and TGFB (Chen et al., 2016). The role that HSP10 plays in ruminant pregnancy is yet unclear. However, Forde et al. (2015) demonstrated that it was produced by both the conceptus and endometrium during early pregnancy in cattle. Clearly, the function of this unique extracellular chaperonin is an area deserving further investigation.

Shortly after trophoblast protein 1 (TP1) was sequenced and determined to belong to the Type I IFN family (Imakawa et al., 1987), several researchers demonstrated that many IFN-stimulated genes (ISG) were induced in the uterus in response to conceptus signaling (see Ott and Gifford, 2010; Ott et al., 2014). However, because most work during this time was unable to detect IFNT in the peripheral circulation or accumulating in tissues outside of the uterus, the central dogma developed that IFNT acted locally on the uterus (Bazer, 2015). This contrasts with humans, where conceptus human chorionic gonadotropin (hCG) acts directly on the corpus luteum. This concept was further strengthened by the fact that the luteolytic signal in ruminants $\left(\mathrm{PGF}_{2 \alpha}\right)$ was derived from the uterus, whereas it originated in the ovary of humans. This paradigm shifted when it was determined that many of the ISG induced in the uterus during early pregnancy in ruminants were also induced in peripheral blood leukocytes (Yankey et al., 2001; Han et al., 2006; Gifford et al., 2007). This suggested that either IFNT escaped the uterus or that some intermediary signal was responsible for this increase. Work by Bott et al. (2010) definitively showed that it was the former, and thus it became clear that IFNT acted both locally, to suppress the luteolytic mechanism (and perhaps regulate immune function), and in peripheral tissues and circulating immune cells (Ott et al., 2014). What remains to be determined is the role that activation of ISG in peripheral tissues and circulating immune cells has on maternal physiology. Is activation of components of innate immunity in circulating immune cells designed to counterbalance the selective immunosuppressive effects of progesterone? Systemic immunosuppression during pregnancy would compound the risk that pregnancy imparts to the mother. It may be that the function of activated ISG in the uterus, coupled with locally high progesterone concentrations, differs from that in peripheral immune cells exposed to substantially lower progesterone concentrations. Clearly, much remains to be determined regarding the immunological cross talk between the conceptus and mother during early pregnancy in ruminants.

\section{SUMMARY}

Figure 1 summarizes current results and presents some generalized hypotheses about cross talk between the conceptus and the maternal immune system during early pregnancy in dairy cattle. Immunological signaling associated with the establishment of pregnancy begins at insemination, with robust uterine responses to antigens introduced into the female reproductive tract at mating. The role of this signaling is not clear in cattle, although evidence in other species suggests that it can affect fertility and the quality of the pregnancy. Following ovulation and formation of the corpus luteum, progesterone induces a differentiated secretory function, including induction of immunosuppressive uterine serpins, and selectively suppresses components of the mucosal immune system. Fertilization results in increased expression of chaperonin 10 (HSPE1), which likely induces immune tolerance. Shortly after hatching 
and during the rapid phase of conceptus elongation, signals from the conceptus, including IFNT, PAG, and PG are produced that alter the function of both uterine parenchymal (epithelial, stromal, endothelial) and immune cells. An immediate response is alteration in uterine PGF and PGE production and secretion that results in luteal maintenance. Under high concentrations of progesterone, conceptus signaling result in increased endometrial abundance of MHC II-expressing cells that are likely macrophages or dendritic cells. Furthermore, there is an increase in the abundance of CD45 + cells expressing proteins associated with both NK $\left(\mathrm{CD} 335^{+}\right)$and cytotoxic $\left(\mathrm{CD} 8^{+}\right) \mathrm{T}$ cells, with a significant proportion co-expressing these proteins. Increased expression of lysosomal-associated membrane protein 1 (CD107a) is consistent with degranulation of these cells. Expression of molecules associated with immune tolerance was also elevated, including IDO1, IL10, TGFB, and the cell-surface proteins CTLA4, programmed cell death ligand 1 (PD-L1), and lymphocyte activating gene 3 (LAG3) that likely induce local tolerance. Increased IDO1 may result in higher concentrations of kynurenine that could signal via AHR to induce IL10 and TGFB and promote development of Treg cells, although this has yet to be determined. The function of elevated ISG in the uterus, peripheral

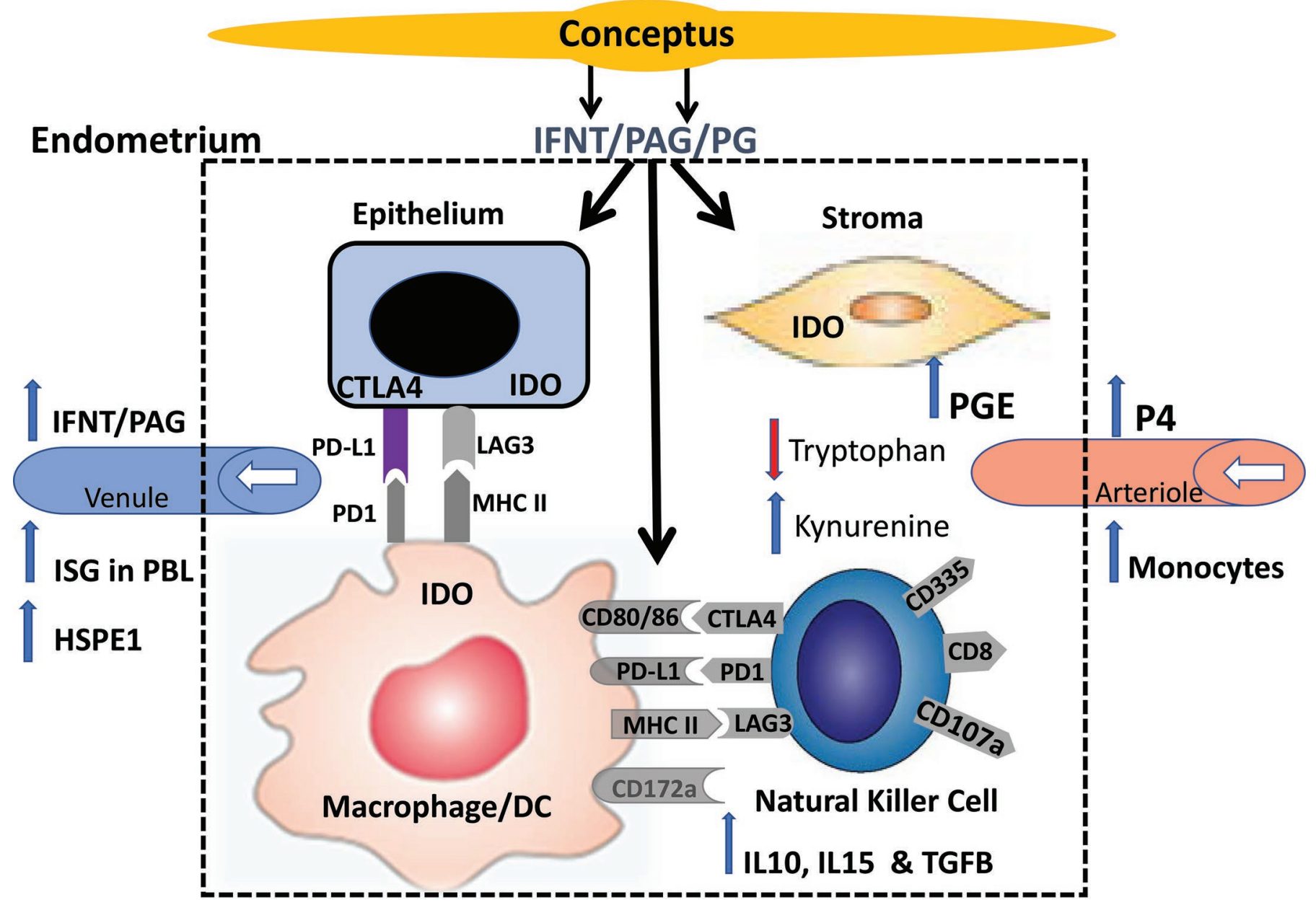

Figure 1. Schematic representation of signaling between the peri-implantation conceptus, uterine endometrium, and circulating immune cells during the period of maternal recognition of pregnancy in cattle. Hormones produced by the conceptus act on a progesterone-primed endometrium to change the proportion and function of immune cells at the fetal-maternal interface. Current evidence indicates these changes include increased abundance of macrophage or dendritic cells (DC) as well as a unique natural killer (NK) cell expressing the CD8 T-cell coreceptor. Furthermore, there is increased expression of several molecules associated with immune tolerance on both immune and nonimmune cells in the endometrium. This is accompanied by increased expression of IFN-stimulated genes (ISG) in the uterus and circulating immune cells. A detailed description of these changes is presented in the summary. IFNT $=$ IFN- $\tau$; PAG $=$ pregnancy-associated glycoprotein; PG $=$ prostaglandin; CTLA4 = cytotoxic T-lymphocyte activating 4; IDO = indoleamine 2,3-dioxygenase; PD-L1 = programmed cell death ligand 1; $\mathrm{PD} 1$ = programmed cell death 1; LAG3 = lymphocyte activating gene 3; MHCII = major histocompatibility complex II; PGE $=$ prostaglandin $\mathrm{E} ; \mathrm{P} 4=$ progesterone; $\mathrm{PBL}=$ peripheral blood leukocytes; HSPE1 $=$ chaperonin 10 ; TGFB $=$ transforming growth factor- $\beta$; CD $=$ cluster of differentiation. 
tissues, and circulating immune cells is not clear but is an area of active investigation. However, the fact that early pregnancy signaling can be detected in the peripheral blood during the first 3 wk of pregnancy may lead to new diagnostic approaches to identify failed inseminations earlier than is currently possible in cattle. A greater understanding of conceptus-induced changes in local and systemic immune function yield greater insight into causes of early embryo loss in cattle as well as suboptimal placental development, which it thought to result in poor postnatal performance.

\section{ACKNOWLEDGMENTS}

This project was supported by Agriculture and Food Research Initiative Competitive Grant no. 2017-6701526455 from the USDA National Institute of Food and Agriculture (Washington, DC).

\section{REFERENCES}

Ball, L. K., G. Evans, and A. Bostrom. 1998. Risky business: Challenges in vaccine risk communication. Pediatrics 101:453-458.

Barcroft, J. 1934. Features in Architecture of Physiological Function. Cambridge University Press. Cambridge, UK.

Barcroft, J., and D. Barron. 1946. Observations on the form and relations of the maternal and fetal vessels in the placenta of sheep. Anat. Rec. 94:569-595.

Barker, D. J. P. 1998. In utero programming of chronic disease. Clin. Sci. (Lond.) 95:115-128.

Bassel, L. L., and J. L. Caswell. 2018. Bovine neutrophils in health and disease. Cell Tissue Res. 371:617-637.

Bauersachs, S., and E. Wolf. 2015. Uterine responses to the preattachment embryo in domestic ungulates: recognition of pregnancy and preparation for implantation. Annu. Rev. Anim. Biosci. 3:489-511.

Bazer, F. W. 2015. History of maternal recognition of pregnancy. Pages 5-26 in Regulation of Implantation and Establishment of Pregnancy in Mammals: Tribute to 45 Year Anniversary of Roger V. Short's "Maternal Recognition of Pregnancy," Advances in Anatomy, Embryology and Cell Biology. R. D. Geisert and F. W. Bazer, ed. Springer, Basel, Switzerland.

Beer, A. E., and R. E. Billingham. 1979. Maternal immunological recognition mechanisms during pregnancy. Pages 293-309 in CIBA Foundation Symposium 64 (new series): Maternal Recognition of Pregnancy. J. Whelan, ed. Exerpta Medica, Oxford, UK.

Bischof, R. J., M. R. Brandon, and C.-S. Lee. 1995. Cellular immune responses in the pig uterus during pregnancy. J. Reprod. Immunol. 29:161-178.

Bott, R. C., R. L. Ashley, L. E. Henkes, A. Q. Antoniazzi, J. E. Bruemmer, G. D. Niswender, F. W. Bazer, T. E. Spencer, N. P. Smirnova, and R. W. Anthony. 2010. Uterine vein infusion of interferon tau (IFNT) extends luteal life span in ewes. Biol. Reprod. 82:725-735.

Boysen, P., G. Gunnes, D. Pende, M. Valheim, and A. K. Storset. 2008. Natural killer cells in lymph nodes of healthy calves express CD16 and show both cytotoxic and cytokine-producing properties. Dev. Comp. Immunol. 32:773-783.

Boysen, P., and A. K. Storset. 2009. Bovine natural killer cells. Vet. Immunol. Immunopathol. 130:163-177.

Bromfield, J. J. 2018. Review: The potential of seminal fluid mediated paternal-maternal communication to optimize pregnancy success. Animal 12:s104-109.

Butler, J. E., W. C. Hamilton, R. G. Sasser, C. A. Ruder, G. M. Hass, and R. J. Williams. 1982. Detection and partial characterization of two bovine pregnancy-specific proteins. Biol. Reprod. 26:925-933.
Cavanagh, A. C. 1996. Identification of early pregnancy factor as chaperonin 10: Implications for understanding its role. Rev. Reprod. 1:28-32.

Cerri, R. L., I. M. Thompson, I. H. Kim, A. D. Ealy, P. J. Hansen, C. R. Staples, J. L. Li, J. E. Santos, and W. W. Thatcher. 2012. Effects of lactation and pregnancy on gene expression of endometrium of Holstein cows at day 17 of the estrous cycle or pregnancy. J. Dairy Sci. 95:5657-5675.

Chen, Q., X. Zhu, R. Chen, J. Liu, P. Liu, A. Hu, L. Wu, H. Hua, and H. Yuan. 2016. Early pregnancy factor enhances the generation and function of CD4+CD25+ regulatory T cells. Tohoku J. Exp. Med. 240:215-220.

Connelley, T. K., C. Longhi, A. Burrells, K. Degnan, J. Hope, A. J. Allan, J. A. Hammond, A. K. Storset, and W. I. Morrison. 2014. NKp46+ CD3+ cells: A novel nonconventional T cell subset in cattle exhibiting both NK cell and T cell features. J. Immunol. 192:3868-3880.

Croy, B. A., A. Waterfield, W. Woodand, and G. J. King. 1988. Normal murine and porcine embryos recruit NK cells to the uterus. Cell. Immunol. 115:471-480.

Croy, B. A., J. Wessels, N. Linton, and C. Tayade. 2009. Comparison of immune cell recruitment and function in endometrium during development of epitheliochorial (pig) and hemochorial (mouse and human) placentas. Placenta 30:S26-31.

Diskin, M. G., M. Parr, and D. Morris. 2011. Embryo death in cattle: An update. Reprod. Fertil. Dev. 24:244-251.

Fair, T. 2015. The contribution of the maternal immune system to the establishment of pregnancy in cattle. Front. Immunol. 6:7.

Forde, N., F. W. Bazer, T. E. Spencer, and P. Lonergan. 2015. 'Conceptualizing' the endometrium: Identification of conceptus-derived proteins during early pregnancy in cattle. Biol. Reprod. 92:156.

Fox, A., J. F. Maddox, M. J. de Veer, and E. N. Meeusen. 2010 $\gamma \delta \mathrm{TCR}+$ cells of the pregnant ovine uterus express variable $\mathrm{T}$ cell receptors and contain granulysin. J. Reprod. Immunol. 84:52-56.

Froehlich, R., N. Hambruch, J.-D. Haeger, M. Dilly, H. Kaltner, H.-J. Gabius, and C. Pfarrer. 2012. Galectin fingerprinting detects differences in expression profiles between bovine endometrium and placentomes as well as early and late gestational stages. Placenta 33:195-201.

Gandhi, R., D. Kumar, E. J. Burns, M. Nadeau, B. Dake, A. Laroni, D. Kozoriz, H. L. Weiner, and F. J. Quintana. 2010. Activation of the aryl hydrocarbon receptor induces human type 1 regulatory $\mathrm{T}$ cell-like and Foxp3+ regulatory T cells. Nat. Immunol. 11:846-853.

Garbayo, J. M., B. Serrano, and F. Lopez-Gatius. 2008. Identification of novel pregnancy-associated glycoproteins (PAG) expressed by the peri-implantation conceptus of domestic ruminants. Anim. Reprod. Sci. 103:120-134.

Gifford, C. A., A. A. Assiri, M. Satterfield, T. E. Spencer, and T. L. Ott. 2008. Receptor transporter protein 4 (RTP4) in endometrium, ovary, and peripheral blood leukocytes of pregnant and cyclic ewes. Biol. Reprod. 79:518-524.

Gifford, C. A., K. Racicot, D. Clark, K. Austin, T. Hansen, M. C. Lucy, C. Davies, and T. L. Ott. 2007. Regulation of interferonstimulated genes in peripheral blood leukocytes in pregnant and bred, nonpregnant dairy cows. J. Dairy Sci. 90:274-280.

Girolami, F., V. Spalenza, L. Manzini, M. Carletti, and C. Nebbia. 2015. Constitutive expression of the AHR signaling pathway in a bovine mammary epithelial cell line and modulation by dioxin-like PCB and other AHR ligands. Toxicol. Lett. 232:98-105.

Gogolin-Ewens, K., E. Meeusen, C.-S. Lee, and M. Brandon. 1989. Expression of CD5, a lymphocyte surface antigen on the endothelium of blood vessels. Eur. J. Immunol. 19:935-938.

Green, J. A., S. Xie, X. Quan, B. Bao, X. Gan, N. Mathialagan, J.-F. Beckers, and R. M. Roberts. 2000. Pregnancy-associated bovine and ovine glycoproteins exhibit spatially and temporally distinct expression patterns during pregnancy. Biol. Reprod. 62:1624-1631.

Groebner, A. E., K. Schulke, J. Schefold, G. Fusch, F. Sinowatz, H. Reichenbach, E. Wolf, H. Meyer, and S. Ulbrich. 2011. Immunological mechanisms to establish embryo tolerance in early bovine pregnancy. Reprod. Fertil. Dev. 23:619-632. 
Han, H., K. Austin, L. E. Rempel, and T. Hansen. 2006. Low blood ISG15 mRNA and progesterone levels are predictive of non-pregnant dairy cows. J. Endocrinol. 191:505-512.

Hansen, P. J. 2010. Medawar redux-An overview on the use of farm animal models to elucidate principles of reproductive immunology. Am. J. Reprod. Immunol. 64:225-230.

Hansen, P. J. 2014. Consequences of interactions between the maternal immune system and the preimplantation embryo in cattle. Pages 141-152 in Reproduction in Domestic Ruminants VIII. J. L. Juengel, A. Miyamoto, L. P. Reynolds, M. F. Smith, and R. Webb, ed. Context Publishing, Packington, Leicestershire, UK.

Hansen, P. J., and S. Tekin. 2005. Pregnancy-associated immunoregulatory molecules discovered in ruminants and their possible relevance to other species. Chem. Immunol. Allergy 88:109-116.

Hassanain, H. H., S. Y. Chon, and S. Gupta. 1993. Differential regulation of human indoleamine 2,3-dioxygenase gene expression by interferons-gamma and-alpha. Analysis of the regulatory region of the gene and identification of an interferon-gamma-inducible DNA-binding factor. J. Biol. Chem. 268:5077-5084.

Hernández-Ochoa, I., B. N. Karman, and J. A. Flaws. 2009. The role of the aryl hydrocarbon receptor in the female reproductive system. Biochem. Pharmacol. 77:547-559.

Hughes, A. L., J. A. Green, J. M. Garbayo, and R. M. Roberts. 2000 Adaptive diversification within a large family of recently duplicated, placentally expressed genes. Proc. Natl. Acad. Sci. USA 97:3319-3323.

Hussen, J., and S. Hans-Joachim. 2017. The contribution of the maternal immune system to the establishment of pregnancy in cattle. Front. Immunol. 8:1875.

Imakawa, K., R. V. Anthony, M. Kazemi, K. R. Marotti, H. G. Polites, and R. M. Roberts. 1987. Interferon-like sequence of ovine trophoblast protein secreted by embryonic trophectoderm. Nature 330:377-379.

Jeddi-Tehrani, M., N. Abbasi, P. Dokouhaki, J. Ghasemi, S. Rezania, M. Ostadkarampour, H. Rabbani, M. A. Akhondi, Z. T. Fard, and A. H. Zarnani. 2009. Indoleamine 2,3-dioxygenase is expressed in the endometrium of cycling mice throughout the oestrous cycle. J. Reprod. Immunol. 80:41-48.

Jiang, Y.-Z., K. Wang, R. Fang, and J. Zheng. 2010. Expression of aryl hydrocarbon receptor in human placentas and fetal tissues. J. Histochem. Cytochem. 58:679-685.

Johnson, W. C., R. G. Bastos, W. C. Davis, and W. L. Goff. 2008. Bovine WC1- $\gamma \delta \mathrm{T}$ cells incubated with IL-15 express the natural cytotoxicity receptor CD335 (NKp46) and produce IFN- $\gamma$ in response to exogenous IL-12 and IL-18. Dev. Comp. Immunol. 32:1002-1010.

Kamat, M. M., S. Vasudevan, S. A. Maalouf, D. H. Townson, J. L. Pate, and T. L. Ott. 2016. Changes in myeloid lineage cells in the uterus and peripheral blood of dairy heifers during early pregnancy. Biol. Reprod. 95:68.

Kane, N., R. Kelly, P. T. Saunders, and H. O. Critchley. 2009. Proliferation of uterine natural killer cells is induced by human chorionic gonadotropin and mediated via the mannose receptor. Endocrinology 150:2882-2888.

Kertz, A. F., T. M. Hill, J. D. Quigley, A. J. Heinrichs, J. G. Linn, and J. K. Drackley.. 2017. A 100-year review: Calf nutrition and management. J. Dairy Sci. 100:10151-10172.

Kwak-Kim, J., S. Bao, S. K. Lee, J. W. Kim, and A. Gilman-Sachs. 2014. Immunological modes of pregnancy loss: Inflammation, immune effectors, and stress. Am. J. Reprod. Immunol. 72:129-140.

Lash, G. E., and J. N. Bulmer. 2011. Do uterine natural killer (uNK) cells contribute to female reproductive disorders? J. Reprod. Immunol. 88:156-164.

Lash, G. E., H. Pitman, H. L. Morgan, B. A. Innes, C. N. Agwu, and J. N. Bulmer. 2016. Decidual macrophages: Key regulators of vascular remodeling in human pregnancy. J. Leukoc. Biol. 100:315-325.

Lee, C. S., K. Gogolin-Ewens, and M. Brandon. 1988. Identification of a unique lymphocyte subpopulation in the sheep uterus. Immunology 63:157.
Leung, S. T., K. Derecka, G. Mann, A. Flint, and C. D. Wathes. 2000. Uterine lymphocyte distribution and interleukin expression during early pregnancy in cows. J. Reprod. Fertil. 119:25-33.

Lewis, S. K., J. L. Farmer, R. C. Burghardt, G. R. Newton, G. A Johnson, D. L. Adelson, F. W. Bazer, and T. E. Spencer. 2007. Galectin 15 (LGALS15): A gene uniquely expressed in the uteri of sheep and goats that functions in trophoblast attachment. Biol. Reprod. 77:1027-1036.

Li, D. D., Y. J. Gao, X. C. Tian, Z. Q. Yang, H. Cao, Q. L. Zhang, B. Guo, and Z. P. Yue. 2013. Differential expression and regulation of Tdo2 during mouse decidualization. J. Endocrinol. 220:73-83.

Lippolis, J. D. 2008. Immunological signaling networks: Integrating the body's immune response. J. Anim. Sci. 86(E. Suppl.):E53-E63.

Mair, K. H., A. Müllebner, S. E. Essler, J. C. Duvigneau, A. K. Storset, A. Saalmüller, and W. Gerner. 2013. Porcine CD8adim/NKp46high NK cells are in a highly activated state. Vet. Res. 44:13.

Mansouri-Attia, N., L. J. Oliveira, N. Forde, A. G. Fahey, J. A Browne, J. F. Roche, O. Sandra, P. Reinaud, P. Lonergan, and T. Fair. 2012. Pivotal role for monocytes/macrophages and dendritic cells in maternal immune response to the developing embryo in cattle. Biol. Reprod. 87:123.

McMahon, C. W., and D. H. Raulet. 2001. Expression and function of NK cell receptors in CD8+ T cells. Curr. Opin. Immunol. 13:465470.

Meeusen, E., R. J. Bischof, and C.-S. Lee. 2001. Comparative T-cell responses during pregnancy in large animals and humans. Am. J. Reprod. Immunol. 46:169-179.

Meeusen, E., A. Fox, M. Brandon, and C. S. Lee. 1993. Activation of uterine intraepithelial $\gamma \delta \mathrm{T}$ cell receptor-positive lymphocytes during pregnancy. Eur. J. Immunol. 23:1112-1117.

Mellor, A. L., and D. H. Munn. 2001. Tryptophan catabolism prevents maternal $\mathrm{T}$ cells from activating lethal anti-fetal immune responses. J. Reprod. Immunol. 52:5-13.

Mezrich, J. D., J. H. Fechner, X. Zhang, B. P. Johnson, W. J. Burlingham, and C. A. Bradfield. 2010. An interaction between kynurenine and the aryl hydrocarbon receptor can generate regulatory $\mathrm{T}$ cells. J. Immunol. 185:3190-3198.

Mori, M., A. Bogdan, T. Balassa, T. Csabai, and J. Szekeres-Bartho. 2016. The decidua - the maternal bed embracing the embryomaintains the pregnancy. Semin. Immunopathol. 38:635-649.

Morton, H. 1987. Ovum factor and early pregnancy factor. Curr. Top. Dev. Biol. 23:73-92.

Morton, H. 1998. Early pregnancy factor and extracellular chaperonin 10 homologue. Immunol. Cell Biol. 76:483-496.

Morton, H., V. Hegh, and G. J. A. Clunie. 1974. Immunosuppression detected in pregnant mice by rosette inhibition. Nature 249:459.

Mujtaba, M. G., J. M. Soos, and H. M. Johnson. 1997. CD4 T suppressor cells mediate interferon tau protection against experimental allergic encephalomyelitis. J. Neuroimmunol. 75:35-42.

Munn, D. H., M. Zhou, J. T. Attwood, I. Bondarev, S. J. Conway, B. Marshall, C. Brown, and A. L. Mellor. 1998. Prevention of allogeneic fetal rejection by tryptophan catabolism. Science 281:11911193.

Nagamatsu, T., and D. J. Schust. 2010. Review: The immunomodulatory roles of macrophages at the maternal-fetal interface. Reprod. Sci. 17:209-218.

Nasar, A., A. Rahman, E. Meeusen, and C.-S. Lee. 2002. Peri-partum changes in the intraepithelial lymphocyte population of sheep interplacentomal endometrium. Am. J. Reprod. Immunol. 47:132141.

Nebert, D. W., and C. L. Karp. 2008. Endogenous functions of the aryl hydrocarbon receptor (AHR): intersection of cytochrome P450 1 (CYP1)-metabolized eicosanoids and AHR biology. J. Biol. Chem. 283:36061-36065.

Odhiambo, J. F., D. H. Poole, L. Hughes, J. M. DeJarnette, E. K. Inskeep, and R. A. Dailey. 2009. Pregnancy outcome in dairy and beef cattle after artificial insemination and treatment with seminal plasma or transforming growth factor beta-1. Theriogenology $72: 566-571$. 
Oliveira, L. J., R. S. N. Barreto, F. Perecin, N. Mansouri-Attia, F. T. V. Pereira, and F. V. Meirelles. 2012. Modulation of maternal immune system during pregnancy in the cow. Reprod. Domest. Anim. 47:384-393.

Oliveira, L. J., and P. J. Hansen. 2008. Deviations in populations of peripheral blood mononuclear cells and endometrial macrophages in the cow during pregnancy. Reproduction 136:481-490.

Oliveira, L. J., and P. J. Hansen. 2009. Phenotypic characterization of macrophages in the endometrium of the pregnant cow. Am. J. Reprod. Immunol. 62:418-426.

Oliveira, L. J., N. Mansourri-Attia, A. G. Fahey, J. Browne, N. Forde, J. F. Roche, P. Lonergan, and T. Fair. 2013. Characterization of the Th profile of the bovine endometrium during the oestrous cycle and early pregnancy. PLoS One 8:e75571.

Oliveira, L. J., S. McClellan, and P. J. Hansen. 2010. Differentiation of the endometrial macrophage during pregnancy in the cow. PLoS One 5:e13213.

Ott, T. L., and C. A. Gifford. 2010. Effects of early conceptus signals on circulating immune cells: lessons from domestic ruminants. Am. J. Reprod. Immunol. 64:245-254.

Ott, T. L., M. Kamat, S. Vasudevan, D. H. Townson, and J. L. Pate. 2014. Maternal immune responses to conceptus signals during early pregnancy in ruminants. Anim. Reprod. 11:237-245.

Peter, A. T. 2013. Bovine placenta: A review on morphology, components, and defects from terminology and clinical perspectives. Theriogenology 80:693-705.

Portus, B. J., T. Reilas, and T. Katila. 2005. Effect of seminal plasma on uterine inflammation, contractility and pregnancy rates in mares. Equine Vet. J. 37:515-519.

Prieto, J. M. B., and M. J. B. Felippe. 2017. Development, phenotype, and function of non-conventional B cells. Comp. Immunol. Microbiol. Infect. Dis. 54:38-44.

Ricote, M., A. C. Li, T. M. Willson, C. J. Kelly, and C. K. Glass. 1998. The peroxisome proliferator-activated receptor- $\gamma$ is a negative regulator of macrophage activation. Nature 391:79-82.

Rumph, J. M., and L. D. Van Vleck. 2004. Age-of-dam adjustment factors for birth and weaning weight records for beef cattle: A review. Genet. Mol. Res. 3:1-17.

Sandra, O., F. Constanta, A. V. Carvalho, C. Eozénoua, D. Valoura, V. Mauffréa, I. Huea, and G. Charpigny. 2015. Maternal organism and embryo biosensoring: Insights from ruminants. J. Reprod. Immunol. 108:105-113.

Sasser, R. G., C. A. Ruder, K. A. Ivani, J. E. Butler, and W. C. Hamilton. 1986. Detection of pregnancy by radioimmunoassay of a novel pregnancy-specific protein in serum of cows and a profile of serum concentrations during gestation. Biol. Reprod. 35:936-942.

Schjenken, J. E., and S. A. Robertson. 2014. Seminal fluid and immune adaptation for pregnancy - Comparative biology in mammalian species. Reprod. Domest. Anim. 49:27-36.

Schlafer, D. H., P. J. Fisher, and C. J. Davies. 2000. The bovine placenta before and after birth: placental development and function in health and disease. Anim. Reprod. Sci. 60-61:145-160.

Scott, J. L., N. Ketheesan, and P. M. Summers. 2009. Spermatozoa and seminal plasma induce a greater inflammatory response in the ovine uterus at oestrus than dioestrus. Reprod. Fertil. Dev. 21:817-826.

Segerson, E. C., and P. Beetham. 2000. High-density ovine endometrial cells exhibit natural killer activity during early pregnancy. Theriogenology 54:1207-1214.

Song, G., F. W. Bazer, and T. E. Spencer. 2007. Pregnancy and interferon tau regulate RSAD2 and IFIH1 expression in the ovine uterus. Reproduction 133:285-295.

Sordillo, L. M. 2016. Nutritional strategies to optimize dairy cattle immunity. J. Dairy Sci. 99:4967-4982.

Spencer, T. E., T. L. Ott, and F. W. Bazer. 1998. Expression of interferon regulatory factors one and two in the ovine endometrium: effects of pregnancy and ovine interferon tau. Biol. Reprod. 58:1154-1162.
Spencer, T. E., O. Sandra, and E. Wolf. 2008. Genes involved in conceptus-endometrial interactions in ruminants: Insights from reductionism and thoughts on holistic approaches. Reproduction 135:165-179.

Storvik, M., P. Huuskonen, P. Pehkonen, and M. Pasanen. 2014. The unique characteristics of the placental transcriptome and the hormonal metabolism enzymes in placenta. Reprod. Toxicol. 47:9-14.

Tekin, Ş., and P. J. Hansen. 2002. Natural killer-like cells in the sheep: Functional characterization and regulation by pregnancy-associated proteins. Exp. Biol. Med. (Maywood) 227:803-811.

Tekin, S., and P. J. Hansen. 2004. Regulation of numbers of macrophages in the endometrium of the sheep by systemic effects of pregnancy, local presence of the conceptus, and progesterone. Am. J. Reprod. Immunol. 51:56-62.

Telgmann, R., R. A. Bathgate, S. Jaeger, G. Tillmann, and R. Ivell. 2003. Transcriptional regulation of the bovine oxytocin receptor gene. Biol. Reprod. 68:1015-1026.

Thompson, I. M., R. L. A. Cerri, I. H. Kim, A. D. Ealy, P. J. Hansen, C. R. Staples, and W. W. Thatcher. 2012. Effects of lactation and pregnancy on metabolic and hormonal responses and expression of selected conceptus and endometrial genes of Holstein dairy cattle. J. Dairy Sci. 95:5645-5656.

Tilburgs, T., B. J. van der Mast, N. M. Nagtzaam, D. L. Roelen, S. A. Scherjon, and F. H. Claas. 2009. Expression of NK cell receptors on decidual $\mathrm{T}$ cells in human pregnancy. J. Reprod. Immunol. $80: 22-32$.

Tugwood, J. D., and C. Montague. 2002. Biology and toxicology of PPARg ligands. Hum. Exp. Toxicol. 21:429-437.

Vacca, P., C. Cantoni, M. Vitale, C. Prato, F. Canegallo, D. Fenoglio, N. Ragni, L. Moretta, and M. C. Mingari. 2010. Crosstalk between decidual NK and CD14+ myelomonocytic cells results in induction of T regs and immunosuppression. Proc. Natl. Acad. Sci. USA 107:11918-11923.

Van Rhijn, I., A. P. Koets, J. S. Im, D. Piebes, F. Reddington, G. S. Besra, S. A. Porcelli, W. van Eden, and V. P. Rutten. 2006. The bovine CD1 family contains group $1 \mathrm{CD} 1$ proteins, but no functional CD1d. J. Immunol. 176:4888-4893.

Vander Wielen, A. L., and G. King. 1984. Intraepithelial lymphocytes in the bovine uterus during the oestrous cycle and early gestation. J. Reprod. Fertil. 70:457-462.

Vasudevan, S., M. M. Kamat, S. S. Walusimbi, J. L. Pate, and T. L. Ott. 2017. Effects of early pregnancy on uterine lymphocytes and endometrial expression of immune-regulatory molecules in dairy heifers. Biol. Reprod. 97:104.

von Rango, U., C. A. Krusche, H. M. Beier, and I. Classen-Linke. 2007. Indoleamine-dioxygenase is expressed in human decidua at the time maternal tolerance is established. J. Reprod. Immunol. $74: 34-45$

Walker, C. G., S. Meier, M. D. Littlejohn, K. Lehnert, J. R. Roche, and M. D. Mitchell. 2010. Modulation of the maternal immune system by the pre-implantation embryo. BMC Genomics 11:474.

Wallace, R. M., K. G. Pohler, M. F. Smith, and J. A. Green. 2015. Placental PAGs: gene origins, expression patterns, and use as markers of pregnancy. Reproduction 149:R115-R126.

Wegmann, T. G., H. Lin, L. Guilbert, and T. R. Mosmann. 1993. Bidirectional cytokine interactions in the maternal-fetal relationship: is successful pregnancy a TH2 phenomenon? Immunol. Today $14: 353-356$.

Wooding, F. B. P., R. M. Roberts, and J. A. Green. 2005. Light and electron microscope immunocytochemical studies of the distribution of pregnancy associated glycoproteins (PAGs) throughout pregnancy in the cow: possible functional implications. Placenta $26: 807-827$.

Yankey, S. J., B. A. Hicks, K. G. Carnahan, A. M. Assiri, S. J. Sinor, K. Kodali, J. N. Stellflug, and T. L. Ott. 2001. Expression of the antiviral protein $\mathrm{Mx}$ in peripheral blood mononuclear cells of pregnant and bred, non-pregnant ewes. J. Endocrinol. 170:7-11. 